\title{
The effect of age on the fatty acids composition in wild boar (Sus scrofa) hunted in the southwest region of Slovakia
}

\author{
Branislav Gálik ${ }^{1}$, Peter Šmehýl ${ }^{2}$, Jozef Gašparík ${ }^{2}$, Juraj Candrák ${ }^{3}$, Andrej Jahnátek ${ }^{4}$, \\ Daniel Bíro ${ }^{1}$, Michal Rolinec ${ }^{1}$, Miroslav Juráček ${ }^{1}$, Milan Šimko ${ }^{1}$ \\ Slovak University of Agriculture in Nitra, \\ ${ }^{1}$ Faculty of Agrobiology and Food Resources, Department of Animal Nutrition, \\ ${ }^{2}$ Faculty of Agrobiology and Food Resources, Department of Poultry Science and Small Animal Husbandry, \\ ${ }^{3}$ Faculty of Agrobiology and Food Resources, Department of Genetics and Breeding Biology, \\ ${ }^{4}$ Faculty of Economics and Management, Department of Economics, Nitra, Slovak Republic \\ Received December 5, 2017 \\ Accepted April 3, 2018
}

\begin{abstract}
The aim of the study was to analyse the fatty acid profile of wild boar (Sus scrofa) meat. The samples were obtained from the mountain Tríbeč (southwest part of the Slovak Republic). A total of 36 samples in 3 age categories of meat were analysed. The effect of age on the intramuscular (IMF) fat content was analysed. The highest $(P<0.05)$ IMF content was found in the samples from the youngest animals $(18.07 \%)$, the lowest $(P<0.05)$ in the sub-adult animals. Significant $(P<0.05)$ differences were found in palmitic acid $(\mathrm{C} 16: 0)$. Significant decrease of heptadecanoic acid (C17:0) as an effect of age was analysed in the samples. Of the important fatty acids, the most abundant in all age categories of wild boar were oleic (C18:1 cis 9), palmitic (C16:0), and linolelaidic acid (C18:2 cis n6). Differences in the content of mentioned acids were significant $(P<0.05)$. In $\alpha$-linolenic and $\gamma$-linoleic acids, non-significant $(P>0.05)$ differences were detected. Significant differences $(P<0.05)$ between age categories were found in cis-11-eicosenoic (C20:1 n9) and cis-11,14-eicosadienoic acids (C20:2 n6). Significant differences $(P<0.05)$ were found in PUFA (polyunsaturated fatty acids), MUFA (monounsaturated fatty acids), and SFA (saturated fatty acids) concentrations. The highest PUFA content was typical for the samples from the oldest animals, MUFA from the sub-adults, and SFA from the youngest wild boar. More significant results were observed in the normalized data with the factor component scores. The wild boar fatty acid profile is significantly affected by age.
\end{abstract}

Game animals, meat, muscle, fat, profile

Recently, consumers have been looking for non-traditional foods as well as meat from wild animals for their specific nutritional and dietetic properties. There is an increased interest in meat from animals kept in conditions close to the nature (Vergara et al. 2003; Soriano et al. 2006). Meat from wild animals is a very good source of essential polyunsaturated fatty acids (Strazdina et al. 2012). Wild boar meat is typically with a lower proportion of saturated fatty acids, and a higher quality of unsaturated fatty acids (Dimatteo et al. 2003). However, the fatty acid profile in wild boar meat is affected by many factors such as age, sex and hunting period, but mainly the month of the hunting season and the environmental conditions (Ramanzin et al. 2010; Russo et al. 2017).

\section{Materials and Methods}

Wild boar (Sus scrofa)

In the experiment 36 carcasses of wild boar (Sus scrofa) were analysed. The carcass samples were collected from a collective hunting during the winter of 2015 in the territory of the mountain range Tríbeč (an area of $550 \mathrm{~km}^{2}$ ) situated in the southwest part of the Slovak Republic (GPS 48.464677, 18.457969). The territory 
is covered mainly with oak forest providing optimal food conditions for the wild boar. Besides the natural food sources, a supplementary diet was served to the animals during the winter period. Maize grain and maize silage were used as a common supplementary diet. The fatty acid profile of maize grain and maize silage are shown Table 1. A total of 36 animals of both sexes and 3 age categories (the youngest: 10-12 months of age, sub-adult 22-24 months of age, and adult 34-36 months of age) were used in the trial, 6 males and 6 females in the each category.

Table 1. Fatty acid profile of maize grain and maize silage.

\begin{tabular}{lcc}
\hline \multirow{2}{*}{ Fatty acid } & Maize grain & \multicolumn{2}{c}{ Maize silage } \\
\cline { 2 - 3 } C12:0 & \multicolumn{2}{c}{$\%$ of total fatty acids } \\
\hline C14:0 & n.d. & 0.20 \\
C16:0 & n.d. & 0.24 \\
C16:1 & 12.94 & 13.68 \\
C17:0 & 0.12 & 0.27 \\
C18:0 & 0.08 & n.d. \\
C18:1 & 1.87 & 2.62 \\
C18:2 & 30.12 & 22.96 \\
C18:3 & 51.06 & 46.05 \\
C20:0 & 1.71 & 6.45 \\
C20:1 & 0.41 & 0.63 \\
C22:0 & 0.29 & 0.22 \\
C24:0 & 0.13 & 0.36 \\
PUFA & 0.20 & 0.60 \\
MUFA & 52.77 & 53.20 \\
SFA & 30.53 & 23.45 \\
En6/n3 & 15.63 & 18.33 \\
PUFA & 29.83 & 6.6 \\
\hline
\end{tabular}

PUFA - polyunsaturated fatty acids; MUFA - monounsaturated fatty acids; SFA - saturated fatty acids; n.d. - not detected

\section{Sampling and chemical analysis}

The samples for chemical analysis were collected from musculus semimembranosus immediately after the shooting and gutting. The content of dry matter, crude fat and fatty acid profile were analysed in the samples after lyophilisation at $-40{ }^{\circ} \mathrm{C}$ (ILSHIN Freez Dryer, ilShinBioBase, South Korea). Standard laboratory methods and procedures (AOAC 2000) were used in the Laboratory of Quality and Nutritive Value of Feeds (Department of Animal Nutrition, Faculty of Agrobiology and Food Resources, Slovak University of Agriculture in Nitra, Slovak Republic). The dry matter content was determined by continual drying $\left(103 \pm 2{ }^{\circ} \mathrm{C}\right)$ till the constant weight; the crude fat content was determined by extraction according to the Soxhlet principle. For the characteristics of lipid fraction, triglycerides were hydrolysed to glycerol and free fatty acids. Methyl esters were then derived from fatty acids. After their preparation the acids were separated on the basis of carbon number and level of unsaturation by gas chromatography fitted with a flame-ionization detector (FID). For the identification of fatty acids, a 37-component mixture (Supleco 47885-U) was used. Standard solution was diluted with $10 \mathrm{ml}$ of hexane; $0.2 \mathrm{~g}$ of fat was diluted in $5 \mathrm{ml}$ of $\mathrm{n}$-hexane, and $1 \mathrm{ml}$ of $2 \mathrm{~N}$ potassium hydroxide in methanol was added. The analytic tube was heated for $30 \mathrm{~s}$ at $60{ }^{\circ} \mathrm{C}$ in a water bath. After $1 \mathrm{~min}, 2 \mathrm{ml}$ of $1 \mathrm{~N}$ hydrochloric acid were added. The top layer was transferred in a vial and placed to the autosampler. The fatty acid content asa percentage in crude fat was determined on the device Agilent 6890A GC (Agilent Technologies, USA).

\section{Statistical analysis}

Fatty acid compositions were described using summary statistics and distribution analysis. The principal component analysis (PCA) method was applied to analyse the detailed study of the fatty acid compositions. The PCA was used to convert a large set of observations of correlated variables into a smaller set of values of linearly uncorrelated variables. Graphical expressions of the PCA results for the individual relationships were illustrated. Analysis of variance (ANOVA) with the age group and sex as fixed effects was used for the original fatty acid data and for the normalized fatty acid data. The original data were transformed due to maintaining the normality of fatty acid data. Additionally the factor component scores as linear regressions were included into the final ANOVA model. All data were analysed with the SAS statistical package (SAS 9.2) and with the statistical package XLSTAT 2017.

Fixed linear model for the analysis of fatty acid traits (original and normalized data):

$$
\begin{array}{cl}
\mathrm{Y}_{\mathrm{ijk}}=A G E_{\mathrm{i}}+\mathrm{SEX}_{\mathrm{j}}+\mathrm{e}_{\mathrm{ijk}} & (1,1 \mathrm{a}) \\
\mathrm{Y}_{\mathrm{ijk}} & - \text { fatty acid traits, composite traits } \\
\mathrm{AGE}_{\mathrm{i}} & - \text { age group (fixed effect, } \mathrm{i}=1,2,3) \\
\mathrm{SEX}_{\mathrm{j}} & - \text { sex (fixed effect, } \mathrm{j}=1,2) \\
\mathrm{e}_{\mathrm{ijk}} & - \text { random residual effect }
\end{array}
$$




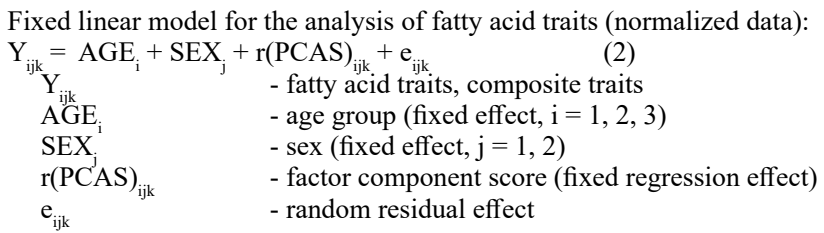

The data used for statistical analyses represent means of the values obtained from 10 animals (5 male and 5 female) from each group. To calculate basic statistic characteristics, to determine significance of differences and to compare results descriptive statistics, ANOVA and F-test were performed at levels of $P<0.05$ and $P<0.01$.

\section{Results}

The fatty acid profile of analysed samples is shown in Table 2. The content of intramuscular fat in analysed meat ranged from $10.73 \%$ (sub-adult boar) to $18.07 \%$ (the youngest boar). Significant $(P<0.01)$ differences between age groups were found in the content of palmitic acid (C16:0). The highest percentage was found in the samples from the youngest boar $(21.39 \%)$ and the lowest in the samples from the oldest one $(17.92 \%)$. Significance $(P<0.05$ and $P<0.01)$ was determined according to the linear models in heptadecanoic acid (C17:0). A tendency $(P>0.05)$ of decreasing stearic acid (C18:0) was detected in the analysed samples. In the oleic acid (C18:1 cis 9) percentage, the lowest $(P<0.05, P<0.01)$ values were found in the youngest wild boar $(42.49 \%)$ in comparison with the sub-adult $(45.81 \%)$ and adult $(44.03 \%)$ age groups. Oleic acid was detected as a major fatty acid in the analysed samples. In linolelaidic acids (C18:2 cis n6), significant $(P<0.01)$ differences between the age groups were found. Only in sub-adults $\gamma$-linoleic acid $(\mathrm{C} 18: 3 \mathrm{n} 6)$ was detected in trace amounts. In $\alpha$-linolenic acid (C18:3 n3) non-significant $(P>0.05)$ differences were found. A tendency $(P>0.05)$ to the highest concentration was detected in the oldest group of wild boar. Significant $(P<0.01, P<0.05)$ differences in cis-11-eicosenoic (C20:1 n9) and cis-11,14-eicosadienoic (C20:2 n6) acids were analysed. In $\mathrm{C} 20: 1 \mathrm{n} 9$ concentration, the highest $(P<0.01, P<0.05)$ values were found in the oldest age group (34-36 months of age) of boar, the same in C20:2 n6 concentration. In eicosapentaenoic acid $(\mathrm{C} 20: 5 \mathrm{n} 3)$ only a tendency $(P>0.05)$ to the highest concentration was found in samples of the youngest animals (10-12 months of age). In the concentrations of other fatty acids, non-significant $(P>0.05)$ differences were detected. Significantly $(P<0.01)$ the highest content of polyunsaturated fatty acids (PUFA) was typical for the oldest age group (34-36 months of age), the lowest for the samples from sub-adult animals $(22-24$ months of age). However, the highest $(P<0.01)$ monounsaturated fatty acid value was found in the sub-adult wild boar, in the samples from 12-24-month-old animals. In saturated fatty acids (SFA) content, a significant $(P<0.05, P<0.01)$ decrease was detected as an effect of age in wild boar. In ratios $n 3 / \mathrm{n} 6$ or $n 6 / \mathrm{n} 3$ fatty acids, non-significant $(P>0.05)$ differences were analysed for the all linear models. The model $(2)$ reached the best explanation of variance analysed among the analysed traits (Table 3 ). The highest values $(0.92,0.85,0.91)$ were observed for PUFA, MUFA and. Only the content of the intramuscular fat did not achieve such explanation of variance. Separately, the first two main components of PCA accounted for $57 \%$ of the total variation (Plate VIII, Fig. 1).

\section{Discussion}

The quality of wild boar meat depends on many factors (Hutařová et al. 2014). The age of the animal has a significant effect on the intramuscular fat content (Russo et al. 2017). Wild boar meat is typically with an average fat content of $2.82 \%$, higher than the intramuscular fat content in elk, deer, and roe deer (Strazdina et al. 2012). In our results, 
Table 2. Fatty acid profile in the youngest, sub-adult and adult wild boar (Sus scrofa) as \% of total fatty acids.

\begin{tabular}{|c|c|c|c|c|c|c|c|c|c|}
\hline \multirow{2}{*}{ Trait } & \multicolumn{2}{|c|}{ The youngest $(\mathrm{n}=12)$} & \multicolumn{2}{|c|}{ Sub-adults $(\mathrm{n}=12)$} & \multicolumn{2}{|c|}{ Adults $(\mathrm{n}=12)$} & \multirow{2}{*}{$\mathrm{P}^{\mathrm{a}}$} & \multirow{2}{*}{$\mathrm{P}^{\mathrm{b}}$} & \multirow{2}{*}{$\mathrm{P}^{\mathrm{c}}$} \\
\hline & mean & S.D. & mean & S.D. & mean & S.D. & & & \\
\hline C10:0 & 0.02 & 0.0381 & 0.03 & 0.0379 & 0.01 & 0.0257 & - & - & - \\
\hline $\mathrm{C} 12: 0$ & 0.03 & 0.0473 & 0.02 & 0.0328 & 0.01 & 0.0261 & - & - & - \\
\hline $\mathrm{C} 14: 0$ & 1.14 & 0.2677 & 0.97 & 0.0919 & 0.92 & 0.0914 & - & - & + \\
\hline C15:0 & 0.10 & 0.0498 & 0.09 & 0.0227 & 0.05 & 0.0470 & - & - & ++ \\
\hline $\mathrm{C} 16: 0$ & 21.39 & 2.3955 & 19.35 & 0.7369 & 17.92 & 0.6443 & ++ & ++ & ++ \\
\hline C16:1 & 2.63 & 0.3012 & 3.06 & 0.2642 & 2.83 & 0.4378 & - & - & - \\
\hline $\mathrm{C} 17: 0$ & 0.47 & 0.0737 & 0.4 & 0.0349 & 0.36 & 0.0474 & + & + & ++ \\
\hline C18:0 & 8.41 & 2.0639 & 7.37 & 0.7079 & 6.99 & 0.4960 & - & - & - \\
\hline C18:1 trans 9 & n.d. & n.d. & n.d. & n.d. & 0.23 & 0.3941 & \multicolumn{3}{|c|}{ not analysed } \\
\hline $\mathrm{C} 18: 1$ cis 9 & 42.49 & 3.0781 & 45.81 & 0.4380 & 44.03 & 0.6945 & + & ++ & ++ \\
\hline $\mathrm{C} 18: 2$ cis n6 & 14.96 & 1.1362 & 12.94 & 1.2636 & 16.81 & 1.4170 & ++ & ++ & ++ \\
\hline C18:3 n6 & n.d. & n.d. & 0.02 & 0.0380 & n.d. & n.d. & \multicolumn{3}{|c|}{ not analysed } \\
\hline C18:3 n3 & 0.84 & 0.2256 & 0.75 & 0.1539 & 0.94 & 0.1283 & - & - & - \\
\hline C20:0 & 0.13 & 0.0219 & 0.14 & 0.0190 & 0.14 & 0.0193 & - & - & + \\
\hline C20:1 n9 & 0.89 & 0.1620 & 1.51 & 0.2065 & 1.53 & 0.3906 & ++ & ++ & + \\
\hline $\mathrm{C} 20: 2 \mathrm{n} 6$ & 0.48 & 0.0429 & 0.44 & 0.0516 & 0.59 & 0.0879 & ++ & ++ & ++ \\
\hline $\mathrm{C} 21: 0$ & n.d. & n.d. & n.d. & n.d. & 0.04 & 0.0586 & \multicolumn{3}{|c|}{ not analysed } \\
\hline $\mathrm{C} 20: 3 \mathrm{n} 6$ & 0.12 & 0.0480 & 0.07 & 0.0538 & 0.09 & 0.0686 & - & - & - \\
\hline C20:4 n6 & 0.46 & 0.2171 & 0.4 & 0.1422 & 0.51 & 0.1392 & - & - & - \\
\hline $\mathrm{C} 20: 3 \mathrm{n} 3$ & 0.10 & 0.0532 & 0.07 & 0.0587 & 0.14 & 0.0167 & - & - & - \\
\hline $\mathrm{C} 20: 5 \mathrm{n} 3$ & 0.07 & 0.0716 & 0.01 & 0.0245 & n.d. & n.d. & - & - & + \\
\hline C22:1 n9 & n.d. & n.d. & n.d. & n.d. & 0.01 & 0.0220 & \multicolumn{3}{|c|}{ not analysed } \\
\hline C23:0 & n.d. & n.d. & n.d. & n.d. & 0.01 & 0.0147 & \multicolumn{3}{|c|}{ not analysed } \\
\hline $\mathrm{C} 24: 0$ & n.d & n.d. & 0.10 & 0.1158 & n.d. & n.d. & \multicolumn{3}{|c|}{ not analysed } \\
\hline PUFA & 17.03 & 1.7195 & 14.7 & 1.5810 & 19.08 & 1.4118 & ++ & ++ & ++ \\
\hline MUFA & 46.04 & 3.0338 & 50.39 & 0.5492 & 48.62 & 1.0478 & ++ & ++ & ++ \\
\hline SFA & 31.69 & 4.6709 & 28.48 & 1.3032 & 26.45 & 1.0895 & + & ++ & ++ \\
\hline$\sum \mathrm{n} 3 / \sum \mathrm{n} 6$ & 0.06 & 0.0175 & 0.06 & 0.0105 & 0.06 & 0.0088 & - & - & - \\
\hline$\sum \mathrm{n} 6 / \sum \mathrm{n} 3$ & 17.60 & 6.3274 & 17.25 & 2.7547 & 16.97 & 2.7632 & - & - & - \\
\hline IM Fat $\%$ & 18.07 & 5.7704 & 10.73 & 2.7943 & 10.74 & 2.9567 & ++ & ++ & + \\
\hline
\end{tabular}

PUFA - polyunsaturated fatty acids; MUFA - monounsaturated fatty acids; SFA - saturated fatty acids; IM intramuscular; S.D. - standard deviation; $\mathrm{P}^{\mathrm{a}}$ - original data; $\mathrm{P}^{\mathrm{b}}$ - normalized data; $\mathrm{P}^{\mathrm{c}}$ - transformed data (factor component scores included); $1^{\text {st }}$ group - the youngest; $2^{\text {nd }}-$ sub-adult; $3^{\text {rd }}$ - adult

significantly $(P<0.01, P<0.05)$ the highest intramuscular fat content was found in the samples from adult wild boar, and lower in sub-adults and boar in the youngest group. This finding is in contrast with the results of Dannenberg et al. (2013) who reported a higher percentage in the adults compared to the young wild boar. During recent years, many papers have reported the fatty acid profile of different wild boar muscles (Dimatteo et al. 2003; Marsico et al. 2007; Razmaite et al. 2012; Strazdina et al. 2013; Russo et al. 2017; Pedrazzoli et al. 2017). The results of many studies showed that the most abundant fatty acids in wild boar meat are palmitic (C16:0) and stearic (C18:0) acids (Pedrazzoli et al. 2017). However, in our experiment, the most abundant acids in analysed muscle of wild boar were palmitic (C16:0), oleic (C18:1 cis 9) and linolelaidic (C18:2 cis n6) acids. For palmitic acid (C16:0), very similar values and the same tendencies as the effect of age 
were found when compared with data reported by Pedrazzoli et al. (2017). However, Dimatteo et al. (2003) reported a markedly lower concentration of this fatty acid in wild boar meat. A non-significant decrease of stearic acid (C18:0) was typical for the analysed samples, however, an increase of this fatty acid in wild boar was reported by Russo et al. (2017). Lower stearic acid concentrations in wild boar was reported by Pedrazzoli et al. (2017). In the analysed data, the important fatty acid in the samples was oleic acid (C18:1 cis 9). The concentration of oleic acid in the wild boar meat and fat was variable during the year. During the winter, higher concentration is typical compared to other parts of the year. The fat content in young and sub-adult wild boar often ranged between 35 and $30 \%$. The oleic acid concentration is typically higher in younger boar (Russo et al. 2017). Russo et al. (2017) published similar results for linolelaidic acid (C18:2 cis n6) compared to our findings as the effect of wild boar's age. Razmaite et al. (2012), analysed the fatty acid profile of wild boar meat in different hunting periods, and reported lower concentrations than we found. The concentrations of essential $\alpha$-linolenic (C18:3 n3) and $\gamma$-linoleic (C18:3 n6) fatty acids were very low in the wild boar meat (Russo et al. 2017). In our experiment, C18:3 n6 was detected only in the $2^{\text {nd }}$ age group. In the arachidic acid (C20:0) concentrations, lower values were found in comparison with the results of Russo et al. (2017). According to our findings, a decrease of eicosenoic acid (C20:1 n9) was noted with the increasing of age. Our results for eicosadienoic acid (C20:2 n6) fatty acid are in the contrast with the results of Russo et al. (2017). The PUFA concentration is affected by age (Russo et al. 2017) and the hunting period (Razmaite et al. 2012). The analysed data showed that the PUFA concentration has an increasing tendency during the life span of the wild boar. The MUFA profile is affected significantly by age; a higher MUFA concentration is typical for wild boar older than 24 months (Pedrazzoli et al. 2017). Body weight also has a significant effect on the MUFA profile in wild boar (Razmaite et al. 2012). Pedrazzoli et al. (2017) reported that total saturated fatty acid (SFA) ranged from 33.90 to $37.62 \%$ in wild boar. These results are very similar to the findings in samples from our experiment, where the SFA contents were between 26.45 and $31.69 \%$. The analysed data of PCA for the fatty acid content (Plate VIII, Fig. 1) were lower compared to the results of Šnirc et al. (2016). The results cannot be directly compared with the evaluation of the effect of different curing methods on the fatty acid composition. The wild boar fatty acids profile is significantly affected by age. However, additional research regarding the effect of feeds on the fatty acids profile in wild boar is needed.

\section{Acknowledgements}

This study was supported by Scientific Grant Agency of the Ministry of Education, Science, Research and Sport of the Slovak Republic and Slovak Academy of Sciences (project VEGA n. 1/0511/15)

\section{References}

Dannenberg D, Nuernberg G, Nuernberg K, Haegemann E 2013: The effects of gender, age and region on marcoand micro-nutrient contents and fatty acid profiles in the muscles of roe deer and wild boar in MecklenburgWestern Pomerania (Germany). Meat Sci 94: 39-46

Dimatteo S, Marciso G, Facciolongo AM, Ragni M, Zezza F 2003: Chemical and fatty acid composition of meat of wild boars fed on diets containing polyunsaturated fatty acids. Italian J Anim Sci 2: 418-420

Hutařová Z, Bořilová G, Svobodová I, Večerek V, Forejterk P, Hulánková R, Maršálek P 2014: Effect of storage conditions on the biogenic amine content in wild boar meat. Acta Vet Brno 83: 61-65

Marsico G, Rasulo A, Dimatteo S, Tarricone S, Pinto F, Ragni M 2007: Pig, F1 (wild boar x pig) and wild boar meat quality. Italian J Anim Sci 6: 701-703

Pedrazzoli M, Dal Bosco A, Castellini C, Ranussi D, Mattioli S, Pauselli M, Roscini V 2017: Effect of age and feeding area on meat quality of wild boars. Italian J Anim Sci 16: 353-362

Ramanzin A, Amici A, Casoli C, Esposito L, Lupi P, Marsico G, Mattiello S, Olivieri O, Ponzetta MP, 
Russo C, Trabalza Marinucci M 2010: Meat from wild ungulates: ensuring quality and hygiene of an increasing resource. Italian J Anim Sci 9: 318-331

Razmaite V, Švirmickas GJ, Šiukščius A 2012: Effet of weight, sex and hunting period on fatty acid composition of intramuscular and subcutaneous fat from wild boar. Italian J Anim Sci 11: 174-179

Russo C, Balloni S, Altomonte I, Martini M, Nuvoloni R, Cecchi F, Pedonese F, Salari F, Marilia Sant'ana Da Silva A, Torracca B, Profumo A 2017: Fatty acid and microbial profile of the meat (longissimus dorsi muscle) of wild boar (Sus scropha scropha) hunted in Tuscany. Italian J Anim Sci 16: 1-8

Soriano A, Cruz B, Gomez L, Mariscal C, Ruiz AG 2006: Proteolysis, physicochemical characteristics and free fatty acid composition of dry sausages made with deer (Cerus epalhus) of wild boar (Sus scrofa) meat: A preliminary study. Food Chem 96: 173-184

Strazdina V, Jemeljanovs A, Sterna V 2012: Fatty acids composition of elk, deer, roe deer and wild boar meat hunted in Latvia. Int J Biol Biom Agricul Food Biotechnol Eng 6: 765-768

Strazdina V, Jemeljanovs A, Sterna V, Ikauniece D 2013: Nutrition value of deer, wild boar and beaver meat hunted in Latvia. Int Proc Chem Biol Environ Eng 53: 71-76

Šnirc M, Belej L', Židek R, Bobko M, Kročko M, Haščík P, Golian J, Král M 2016: Influence of different curing methods on the fatty acid composition in sausages prepared from red deer meat. Slovak J Food Sci 10: 585-590

Vergara H, Gallego L, Garcia A, Landete-Castillejos T 2003: Conservation of Cervus elaphus meat in modified atmospheres. Meat Sci 65: 779-783 
Plate VIII

Gálik B. et al.: The effect of age ... pp. 85-90

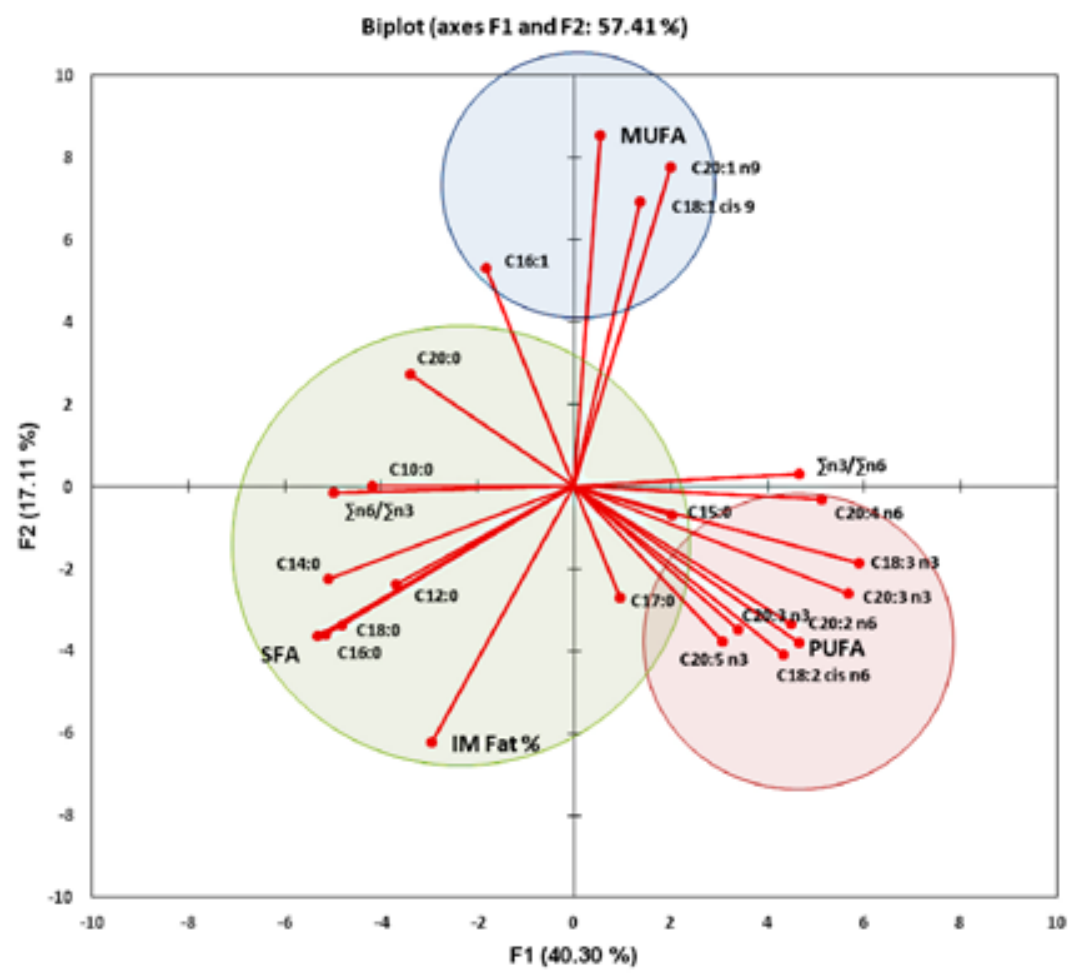

Fig. 1. Basic principal component analysis results for the fatty acid profiles.

PUFA - polyunsaturated fatty acids; MUFA - monounsaturated fatty acids; SFA - saturated fatty acids; IM - intramuscular fat; F1 - first principal component; F2 - second principal component 